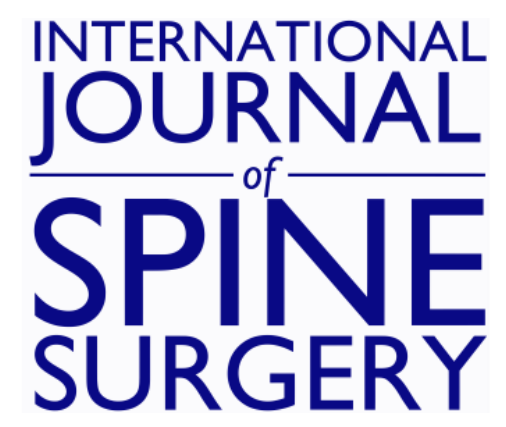

\title{
Sagittal Balance Correction in Lateral Interbody Fusion for Degenerative Scoliosis
}

Daniel J. Blizzard, Michael A. Gallizzi, Charles Sheets, Benjamin T. Smith, Robert E. Isaacs, Megan Eure and Christopher R. Brown

Int J Spine Surg 2016, 10 ()

doi: https://doi.org/10.14444/3029

http://ijssurgery.com/content/10/29

This information is current as of April 25, 2023.

Email Alerts Receive free email-alerts when new articles cite this article. Sign up at:

http://ijssurgery.com/alerts

The International Journal of Soding Surgerght 2397 Waterbury Circle, Suite 1,

Aurora, IL 60504, Phone: +1-630-375-1432

(C) 2016 ISASS. All Rights Reserved. 


\section{Sagittal Balance Correction in Lateral Interbody Fusion for Degenerative Scoliosis}

Daniel J. Blizzard, MD, MHS, ${ }^{1}$ Michael A. Gallizzi, $M D, M S,{ }^{1}$ Charles Sheets, $P T,{ }^{1}$ Benjamin $T$. Smith, DO, ${ }^{1}$ Robert E. Isaacs, MD, ${ }^{2}$ Megan Eure, $M S,{ }^{1}$ Christopher R. Brown, $M D^{1}$

${ }^{1}$ Department of Orthopaedic Surgery, Duke University Medical Center, Durham, NC, USA, 2Department of Surgery, Division of Neurosurgery, Duke University Medical Center, Durham, NC, USA

\section{Abstract}

Background

Sagittal balance restoration has been shown to be an important determinant of outcomes in corrective surgery for degenerative scoliosis. Lateral interbody fusion (LIF) is a less-invasive technique which permits the placement of a high lordosis interbody cage without risks associated with traditional anterior or transforaminal interbody techniques. Studies have shown improvement in lumbar lordosis following LIF, but only one other study has assessed sagittal balance in this population. The objective of this study is to evaluate the ability of LIF to restore sagittal balance in degenerative lumbar scoliosis.

Methods

Thirty-five patients who underwent LIF for degenerative thoracolumbar scoliosis from July 2013 to March 2014 by a single surgeon were included. Outcome measures included sagittal balance, lumbar lordosis, Cobb Angle, and segmental lordosis. Measures were evaluated pre-operative, immediately post-operatively, and at their last clinical follow-up. Repeated measures ANOVAs were used to assess the differences between pre-operative, first postoperative, and a follow-up visit.

Results

The average sagittal balance correction was not significantly different: $1.06 \mathrm{~cm}$ from $5.79 \mathrm{~cm}$ to $4.74 \mathrm{~cm}$ forward. The average Cobb angle correction was 14.1 degrees from 21.6 to 5.5 degrees. The average change in global lumbar lordosis was found to be significantly different: 6.3 degrees from 28.9 to 35.2 degrees.

\section{Conclusions}

This study demonstrates that LIF reliably restores lordosis, but does not significantly improve sagittal balance. Despite this, patients had reliable improvement in pain and functionality suggesting that sagittal balance correction may not be as critical in scoliosis correction as previous studies have indicated.

\section{Clinical Relevance}

LIF does not significantly change sagittal balance; however, clinical improvement does not seem to be contingent upon sagittal balance correction in the degenerative scoliosis population.

The DUHS IRB has determined this study meets criteria for an IRB waiver.

KEYWORDS: LATERAL INTERBODY FUSION, SAGITTAL BALANCE, SCOLIOSIS, LUMBAR LORDOSIS, RETROPERITONEAL APPROACH

\section{Introduction}

Degenerative scoliosis of the lumbar spine occurs as a result of pathological changes in the discs and joints that develop in a previously straight spine. Degenerative scoliosis is commonly seen in up to $68 \%$ of the healthy asymptomatic elderly population and can cause patients to experience variable degrees of pain and disability. ${ }^{1}$ The operative treatment of these disease processes is intended to restore stability, alignment and relieve neural compression.

Traditionally, either a posterior spine fusion (PSF) or anterior lumbar interbody fusion (ALIF) were used 
for operative scoliotic correction. Lateral interbody fusion (LIF) is a newer technique that has grown in popularity among surgeons due to the limited exposure, decreased operative time and avoidance of the risks and morbidities of the anterior approach: visceral injury, post-operative ileus, ventral hernia, and neurovascular injury. ${ }^{2}$ Lateral interbody fusion techniques have been shown to yield higher fusion rates and improvement in lumbar lordosis as well as less morbidity than conventional anterior and posterior approaches. ${ }^{3,4}$

Sagittal balance is the center-of-mass vector of the spine determined by the reciprocal curves of thoracic kyphosis and lumbar lordosis. Restoration of sagittal balance has repeatedly been shown to portend superior outcomes in pain, function, and health-related quality of life following spine surgery. ${ }^{3,5}$ Interbody cages (synthetic implanted scaffolding into the disc spaces) are designed to re-create the natural lordosis of the lumbar spine that is frequently changed by the asymmetric degeneration of the discs and to normalize the overall sagittal balance of the spine.

To date, multiple studies have shown improvement or correction in lumbar lordosis and coronal Cobb angle in patients following lateral interbody fusion. ${ }^{2,6}$ However, despite these demonstrated improvements, there is only limited data evaluating the potential of LIF to restore or improve sagittal balance. In the study herein, the change in sagittal balance and coronal Cobb angle is measured following an LIF with posterior fixation. We hypothesized that patients treated with LIF would have improved radiographic measures post-operatively compared to preoperative.

\section{Materials and Methods}

\section{Subjects}

After institutional review-board approval, a retrospective review was conducted of patients treated by a single surgeon from June 2013 through May 2014 at a Level 1 Academic Center. Our institutional database was searched using International Classification of Disease (ICD) codes to identify patients with a primary diagnosis of degenerative scoliosis and Current Procedural Terminology (CPT) code for anteri- or/lateral lumbar interbody fusion. Further inclusion criteria included pre-operative and post-operative standing, cervical to sacral lateral and posteroanterior (PA) radiographs. Exclusion criteria included patients with prior lumbar instrumentation, known infection, patient age less than 18 , or tumor. These criteria yielded a total of 35 patients.

The medical records for all patients meeting the selection criteria were accessed and reviewed to confirm diagnosis and procedure. For the purposes of this study, scoliosis was defined as a coronal Cobb angle of 10 degrees or more.

\section{Outcome Evaluation}

Pre-operative, post-operative, and subsequent follow-up standing cervical to sacral lateral and PA radiographs were used to assess the following measurements:

Sagittal vertical axis (SVA): Sagittal balance. Measured as the horizontal distance between a plumbline from the middle of the $\mathrm{C} 7$ vertebral body to the posterior-superior sacral endplate. A plumb-line falling anterior to the posterior-superior sacral endplate is considered positive sagittal balance, while a plumb-line falling posterior is considered negative sagittal balance (Figure 1).

Cobb angle: Measured as the angle between a line drawn parallel to the superior endplate of the most cephalad angulated/displaced vertebra and a line drawn parallel to the inferior endplate of the most caudal angulated/displaced vertebra.

Global lumbar lordosis (GLL): Measured as the angle between lines drawn parallel to the superior endplate of L1 and inferior endplate of L5.

Segmental lordosis (SL): Measured as the angle between lines drawn parallel to the superior endplate of the most cephalad vertebra in the fusion construct and the inferior endplate of the caudal most vertebra in the fusion construct.

All measurements were made using Surgimap 2.0 software (MEDICREA, Neyron, Lyon, France) by one of two authors (D.J.B. or M.A.G.). All pre- 
operative images were obtained within 6 months of surgery. All post-operative images were obtained within 2 weeks of surgery. For patients with subsequent standing cervical to sacral imaging, the latest standing film was used for review.

Pelvic incidence, pelvic tilt, and sacral slope were not measured in this study due to significant inter- and intra-observer reliability in preliminary measurements among the authors in this study. This poor repeatability was attributed to inconsistent quality and penetration of the films.

For a subset of patients, pre- and post-operative clinical functionality measures were recorded. These measures include the Oswestry Disability Index (ODI), the short form-12 mental (SF-12M) and physical (SF-12P) composite scores, and the visual analog pain scores for the back (VAS-B) and legs (VAS-A).

\section{Surgical Technique}

When arthrodesis was necessitated at the L5/S1 lev$\mathrm{el}$, anterior lumbar interbody fusion (ALIF) was performed. At all other levels necessitating arthrodesis, extreme lateral interbody fusion (XLIF) (NuVasive Inc., San Diego, CA, U.S.A.) was performed. All patients subsequently underwent posterior percuta-
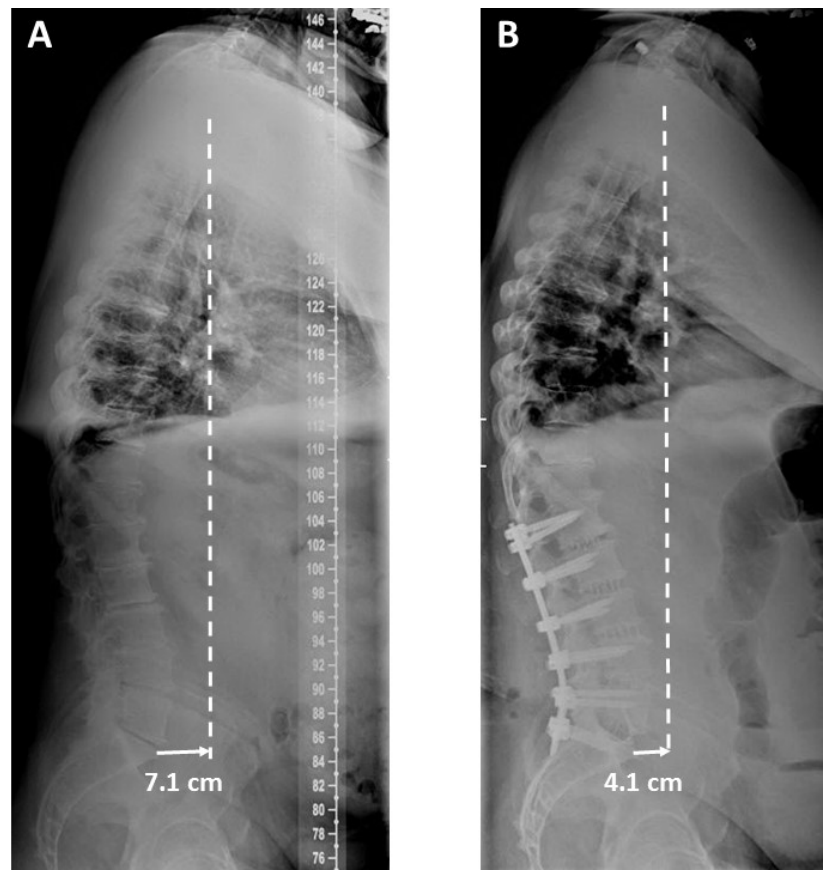

Fig. 1. Pre-operative standing lateral radiograph depicting a sagittal balance of $+7.1 \mathrm{~cm}$. (B) Post-operative radiograph depicting an improvement in sagittal balance to $+4.1 \mathrm{~cm}$ neous instrumentation in a single or subsequent surgical stage.

ALIF was performed using a standard midline retroperitoneal approach in the supine position with anterior longitudinal ligament release, discectomy and cage placement with allograft bone using the $\mathrm{Nu}$ Vasive Brigade System. XLIF was performed in the lateral decubitus position using minimally-invasive instrumentation and neuromonitoring with discectomy followed by placement of a cage with allograft. For lumbar levels, a lateral transpsoas approach was used. For thoracic levels, a lateral transthoracic approach was used without rib resection. No anterior column realignment (ACR) via ALL release was performed for the XLIF levels and no unintentional ALL releases were observed. Posterior instrumentation was placed percutaneously in the prone position using neuromonitoring and fluoroscopy.

\section{Statistical Methods}

Multilevel modeling was used to assess withinsubject changes across the three time periods: preoperative, immediate post-operative, and last postoperative. For all adjusted values less than 0.05 , post-hoc tests for differences at each time point were performed with Tukey correction. All statistical analysis was carried out using the $\mathrm{R}$ statistical package, version 3.0.2, including the packages "nlme" for multilevel modeling and "multcomp" for post hoc testing. ${ }^{7-9}$

\section{Results}

There were a total of 35 subjects ( $68.6 \%$ female), with an average age of 66.0 years (range: $40-83$ years). All patients carried a pre-operative diagnosis of lumbar or thoracolumbar scoliosis and spinal stenosis and 57\% (20/35) carried a concurrent diagnosis of spondylolisthesis. A total of 159 levels were instrumented (4.5 levels/subject): 136 levels with LIF technique and 23 levels with ALIF technique (Table 1). The most common level of fusion was L3-4 followed by L2-3 and L4-5 (Table 2). Mean values and standard errors of the mean are reported in Table 3 and Figure 1 for all radiographic criteria. A baseline difference between PI and GLL of greater than $10^{\circ}$ was found for 28 (85\%) of subjects. The differences in the 
means of the radiographic criteria between timepoints are reported in Table 4.

A significant improvement in Cobb angle was found at both post-operative timepoints from a preoperative angle of $21.6^{\circ}$ to $6.9^{\circ}(\mathrm{p}<0.001)$ and $8.0^{\circ}$ $(\mathrm{p}<0.001)$ for first the first and final follow-up timepoints, respectively. The change in Cobb angle between post-operative timepoints was not significant.

The average pre-operative SVA was $5.79 \mathrm{~cm}$ of positive balance. Although the SVA improved from the pre-operative balance, there was no significant change at either of the post-operative timepoints.

\begin{tabular}{|} 
Table 1. Breakdown of number fusion levels. \\
\begin{tabular}{|l|r|}
\hline Levels of Fusion & No. of Patients \\
\hline 1 & 2 \\
\hline 2 & 3 \\
\hline 3 & 5 \\
\hline 4 & 8 \\
\hline 5 & 8 \\
\hline 6 & 6 \\
\hline $7+$ & 3 \\
\hline
\end{tabular}
\end{tabular}

Table 2. Frequency table of levels fused. All L5-S1 levels are ALIF technique and all other levels are LIF technique.

\begin{tabular}{|l|r|}
\hline T5-6 & 1 \\
\hline T6-7 & 1 \\
\hline T7-8 & 1 \\
\hline T8-9 & 1 \\
\hline T9-10 & 1 \\
\hline T10-11 & 1 \\
\hline T11-12 & 4 \\
\hline T12-L1 & 10 \\
\hline L1-2 & 21 \\
\hline L2-3 & 31 \\
\hline L3-4 & 34 \\
\hline L4-5 & 30 \\
\hline L5-S1 & 23 \\
\hline
\end{tabular}

There was an increase in lordotic angle following surgery with a maximum angle at the first postoperative timepoint for all lordotic measures except SL. GLL significantly changed from $28.9^{\circ}$ preoperatively to $35.2^{\circ}$ at the first post-operative timepoint. Lordosis then slightly decreased at the final post-operative timepoint and was not significantly different than the pre-operative of first postoperative timepoints. SL increased from the preoperative angle at both post-operative timepoints, but not significantly.

There was no significant difference between the two post-operative timepoints for any radiographic measure.

Patient-reported outcomes were measured at baseline and at the final available visit (6 or 12 weeks). Values are reported in Table 5. A statistically significant improvement was found for all variables with the exception of the SF-36 physical subscale (PCS). Clinically significant improvement was noted for the ODI and all pain measures, but not for the PCS.

\begin{tabular}{|c|c|c|c|}
\hline Measures & Time & Mean & SE \\
\hline \multirow{3}{*}{ SVA } & Pre-operative & $5.79 \mathrm{~cm}$ & $0.85 \mathrm{~cm}$ \\
\hline & First post-operative & $5.60 \mathrm{~cm}$ & $0.79 \mathrm{~cm}$ \\
\hline & Final post-operative & $3.81 \mathrm{~cm}$ & $0.99 \mathrm{~cm}$ \\
\hline \multirow{3}{*}{ Cobb } & Pre-operative & $21.6^{\circ}$ & $2.4^{\circ}$ \\
\hline & First post-operative & $6.9^{\circ}$ & $1.8^{\circ}$ \\
\hline & Final post-operative & $8.0^{\circ}$ & $2.3^{\circ}$ \\
\hline \multirow{3}{*}{ GLL } & Pre-operative & $28.9^{\circ}$ & $2.3^{\circ}$ \\
\hline & First post-operative & $35.2^{\circ}$ & $2.2^{\circ}$ \\
\hline & Final post-operative & $32.0^{\circ}$ & $2.8^{\circ}$ \\
\hline \multirow{3}{*}{ LSL } & Pre-operative & $40.0^{\circ}$ & $2.2^{\circ}$ \\
\hline & First post-operative & $46.7^{\circ}$ & $2.0^{\circ}$ \\
\hline & Final post-operative & $45.9^{\circ}$ & $2.6^{\circ}$ \\
\hline \multirow{3}{*}{ SL } & Pre-operative & $33.6^{\circ}$ & $2.2^{\circ}$ \\
\hline & First post-operative & $37.0^{\circ}$ & $2.0^{\circ}$ \\
\hline & Final post-operative & $38.6^{\circ}$ & $2.5^{\circ}$ \\
\hline
\end{tabular}




\section{Discussion}

Degenerative, or denovo, scoliosis typically affects patients beginning in the fifth or sixth decades of life and is the result of asymmetric degeneration of discs, facet joints, and ligaments in the spine resulting in instability. ${ }^{10}$ Similar to adolescent scoliosis, numerous studies have demonstrated that positive sagittal balance in this population leads to inferior physical and social functioning as well as worse pain scores. ${ }^{1,5,11}$ Restoration of sagittal balance has been shown to be an important determinant of symptom improvement. ${ }^{5,11}$ Additionally, patients with degenerative scoliosis have a decreased average lumbar lordosis and thoracic kyphosis compared to their non-

\begin{tabular}{|c|c|c|c|c|}
\hline Measures & Time & Difference & $\begin{array}{l}\text { SE of } \\
\text { difference }\end{array}$ & p-value \\
\hline \multirow{3}{*}{ SVA } & $\begin{array}{l}\text { First post-operative - } \\
\text { pre-operative }\end{array}$ & $-0.99 \mathrm{~cm}$ & $0.77 \mathrm{~cm}$ & 0.40 \\
\hline & $\begin{array}{l}\text { Final post-operative - } \\
\text { pre-operative }\end{array}$ & $-1.98 \mathrm{~cm}$ & $0.97 \mathrm{~cm}$ & 0.10 \\
\hline & $\begin{array}{l}\text { Final - first } \\
\text { post-operative }\end{array}$ & $-0.99 \mathrm{~cm}$ & $0.97 \mathrm{~cm}$ & 0.56 \\
\hline \multirow{3}{*}{ Cobb } & $\begin{array}{l}\text { First post-operative - } \\
\text { pre-operative }\end{array}$ & $-14.7^{\circ}$ & $1.7^{\circ}$ & $<0.001$ \\
\hline & $\begin{array}{l}\text { Final post-operative - } \\
\text { pre-operative }\end{array}$ & $-13.6^{\circ}$ & $2.2^{\circ}$ & $<0.001$ \\
\hline & $\begin{array}{l}\text { Final - first } \\
\text { post-operative }\end{array}$ & $1.1^{\circ}$ & $2.2^{\circ}$ & 0.88 \\
\hline \multirow{3}{*}{ GLL } & $\begin{array}{l}\text { First post-operative - } \\
\text { pre-operative }\end{array}$ & $6.3^{\circ}$ & $2.2^{\circ}$ & 0.01 \\
\hline & $\begin{array}{l}\text { Final post-operative - } \\
\text { pre-operative }\end{array}$ & $3.1^{\circ}$ & $2.8^{\circ}$ & 0.50 \\
\hline & $\begin{array}{l}\text { Final - first } \\
\text { post-operative }\end{array}$ & $-3.2^{\circ}$ & $2.8^{\circ}$ & 0.47 \\
\hline \multirow{3}{*}{ LSL } & $\begin{array}{l}\text { First post-operative - } \\
\text { pre-operative }\end{array}$ & $6.7^{\circ}$ & $2.0^{\circ}$ & 0.002 \\
\hline & $\begin{array}{l}\text { Final post-operative - } \\
\text { pre-operative }\end{array}$ & $5.9^{\circ}$ & $2.5^{\circ}$ & 0.05 \\
\hline & $\begin{array}{l}\text { Final - first } \\
\text { post-operative }\end{array}$ & $-0.7^{\circ}$ & $2.5^{\circ}$ & 0.95 \\
\hline \multirow{3}{*}{ SL } & $\begin{array}{l}\text { First post-operative - } \\
\text { pre-operative }\end{array}$ & $3.4^{\circ}$ & $1.9^{\circ}$ & 0.18 \\
\hline & $\begin{array}{l}\text { Final post-operative - } \\
\text { pre-operative }\end{array}$ & $5.0^{\circ}$ & $2.4^{\circ}$ & 0.10 \\
\hline & Final- first post-operative & $1.6^{\circ}$ & $2.4^{\circ}$ & 0.78 \\
\hline
\end{tabular}

scoliotic peers. ${ }^{12}$ Accordingly, the goal of scoliosis surgery is to correct both the characteristic coronal deformity as well as sagittal balance.

Surgical correction of spinal deformities can be accomplished with an anterior, posterior, lateral, or combination of approaches. Posterior instrumentation using hooks, wires, pedicle screws and rods is the oldest and most common technique for scoliotic correction and has a long record of reliable correct coronal and sagittal deformity. ${ }^{13,14}$ Unlike adolescent scoliosis, degenerative scoliotic curves are more rigid and often necessitate a combined technique of interbody fusion with posterior instrumentation..$^{15}$ Large posterior surgery is associated with significant morbidity including blood loss, wound infection, and anesthesia complications from prolonged duration surgery ${ }^{16,17}$ Similarly, anterior surgery is associated with increased rates of vascular injury, visceral injury, and post-operative ileus. ${ }^{13,18-20}$ Minimallyinvasive techniques have become increasingly popular as they offer the potential for comparable coronal and lordotic correction through interbody fusion, but with less morbidity than traditional open surgical ap-

\begin{tabular}{|l|l|r|r|r|r|r|r|r|}
\hline Table 5. Patient-reported outcome measures. \\
\hline \multirow{2}{*}{ Outcome }
\end{tabular}

Downloaded from http://ijssurgery.com/ by guest on April 25, 2023 
proaches.

In a series of 25 patients with degenerative scoliosis, Dakwar et al. used a hybrid technique of lateral interbody fusion combined with posterior instrumentation and were able to achieve improved sagittal balance in 16 (64\%) patients. ${ }^{21}$ Also using minimallyinvasive lateral interbody fusion, Acosta et al. demonstrated significant improvement in the coronal Cobb angle and segmental lordotic alignment at the levels of instrumentation, but did not show significant improvement in regional lumbar lordosis or global sagittal alignment. ${ }^{22}$ Wang et al. showed significant coronal Cobb correction from 31.4 to 11.5 degrees, but found only an average of 8 degrees of improved lordosis in the thoracolumbar spine. ${ }^{23}$

Karikari et al. also assessed lateral interbody fusion for isolated thoracic and thoracolumbar spine disease and found coronal plane correction of 22 degrees to 14 degrees from pre- to post-operative, respectively. ${ }^{24}$ However, similar to Wang et al., they were unable to significantly change global lordosis going from 39 degrees pre-operatively to 44 degrees post-operatively.

In the study herein, we found that LIF reliably and significantly corrects coronal imbalance and increases lumbar lordosis (GLL). Baghdadi et al. demonstrated significantly improved lumbar lordosis with a $\mathrm{LIF} \pm$ ALIF compared to PSF with a change of 6 degrees in the LIF \pm ALIF cohort and -2 degrees in the PSF cohort. Additionally, they further reported a significant difference in the change in coronal Cobb angle between the cohorts with a 24 degree change in the LIF \pm ALIF cohort and only a 7 degree change in the PSF cohort. Johnson et al. noted significant correction of both the coronal Cobb angle and SL, but were unable to find a significant difference in the GLL or spinopelvic measurments (PI, PT, SS) in their LIF study. Other researchers have affirmed the reliable correction of coronal Cobb angle, but differ on their correction of lumbar lordosis.,24,25 In our study, we found a significant change in GLL from 28.9 degrees pre-operatively to 35.2 degrees at the first post-operative timepoint and a significant improvement in LSL from 40.0 degrees pre-operatively to 46.7 and 45.9 degrees as the first and final postoperative timepoints, respectively.
Although sagittal balance improved post-operatively in this study, the difference was not statistically significant. However, the pre-operative sagittal balance in the study population was only $5.79 \mathrm{~cm}$ anterior to the sacrum. In a 1995 study, Gelb et al. evaluated the sagittal balance of 100 asymptomatic patients over the age of 40 (average age 57) and found it to be $3.2 \pm$ $3.2 \mathrm{~cm}$ anterior to the sacrum. ${ }^{25} \mathrm{In}$ a subsequent study by Hammerberg and Wood, the sagittal balance of 50 asymptomatic patients ages 70-85 was assessed and found to be $4.04 \pm 3.73 \mathrm{~cm} .{ }^{26}$ Additionally they found that age correlated with increasingly anterior sagittal balance as well as decreasing lumbar lordosis. Although it is generally accepted that $\pm 2 \mathrm{~cm}$ of sagittal balance is normal, the age-related increase in sagittal balance should be considered in preoperative planning for scoliosis correction to determine the amount of sagittal correction needed to restore age-appropriate balance. In the present study of patients with a primary diagnosis of degenerative scoliosis, the average pre-operative anterior sagittal balance was within the normal age-adjusted range and the final average sagittal balance of $3.81 \mathrm{~cm}$ was only $0.61 \mathrm{~cm}$ more anterior than the average sagittal balance reported by Gelb et al. ${ }^{25}$ Accordingly, significant sagittal correction was not required in our study population to return them to the age-adjusted normal range.

For all measures in this study with the exception of $\mathrm{SL}$, we found a maximal increase or correction at the first post-operative timepoint and then a subsequent slight decrease or loss of correction at the final postoperative timepoint (Figure 2). The difference between the two post-operative timepoints was not significant for any measure. We believe this effective settling of the measures can be attributed to bony resorption that occurs during arthrodesis. As osteoclasts resorb allograft bone within the cages during the remodeling phase of fusion, the instrumented segment is relatively destabilized and prone to deformation from the musculotendinous forces. Although coronal Cobb angle and sagittal balance are improved to a more physiologically advantageous position following surgery, muscles and tendons do not immediately accommodate the new spinal alignment and impart a deforming force that decreases over time until the muscles are able to relax to the new resting posi- 
tion.

This study has important limitations. First, there are only a limited number of patients for which patientreported outcome data is available. Second, this study was design to evaluate patients undergoing LIF for degenerative scoliosis, not kyphotic or flat-back deformities. Accordingly, the degree of sagittal imbalance in the study population varied, and in many cases was, within the normal range pre-operatively. In patients with only minor imbalance, very little correction would be needed to restore normal balance and such small changes might not be detected without a larger sample size. Although this patient selection limits generalizability to patients with a primary diagnosis of sagittal imbalance or kyphosis, we believe the patient population in this study reflects the majority of patients undergoing LIF. Finally, given the number of subjects, we were unable to perform subgrouping analyses based on commonly described baseline variables. For example, pelvic incidencelumbar lordosis (PI-LL) mismatch of less than 10 degrees was found only $15 \%$ of subjects pre-operatively. Although PI-LL is a well-accepted marker of disease severity, the limited patient population precluded sub-analysis based upon pre-operative disease severity. We recommend that follow-up studies that wish to address this subgroup analysis be performed with larger samples.

The degree of sagittal correction in LIF is contingent upon multiple factors including the lordosis of the

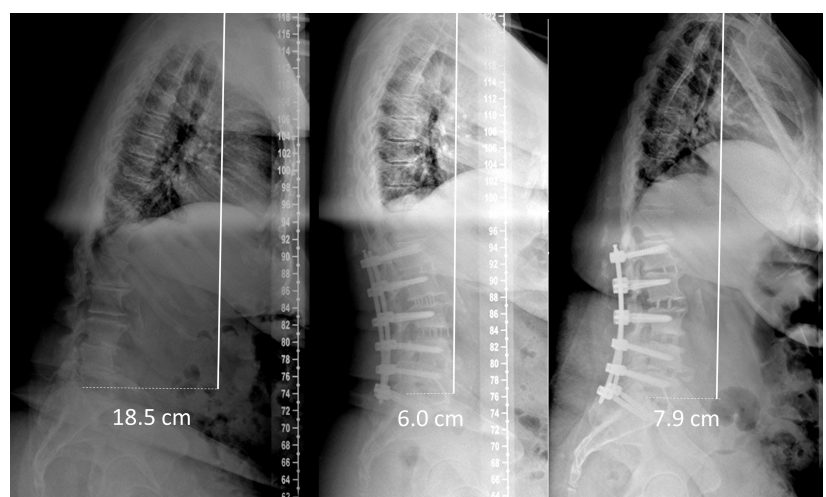

Fig. 2. Case example demonstrating mild loss of correction over time. (A) Pre-operative standing lateral radiograph depicting a sagittal balance of $+18.5 \mathrm{~cm}$. (B) Post-operative radiograph at 6-weeks depicting an improvement in sagittal balance to $+6.0 \mathrm{~cm}$. (C) Post-operative radiograph at 6-months depicting a mild loss of correction to a sagittal balance of $7.9 \mathrm{~cm}$. implanted cage, the integrity of the endplates, the number of levels in the construct, the quality of the vertebral bone, and, most importantly, the degree of pre-operative sagittal imbalance. While coronal correction was readily achieved and lumbar lordosis was significantly increased, very little sagittal correction was obtained and most of our patients remained outside of $\pm 2 \mathrm{~cm}$ of neutral sagittal alignment. However, sagittal correction to neutral alignment may not be required in the degenerative scoliosis population to achieve a favorable result as sagittal balance becomes increasingly positive with age. This conclusion is supported by the patient-reported outcome measures in this study indicating a good clinical result despite correction of sagittal balance to neutral. In instances where kyphosis is the primary disease and the primary goal of surgery is sagittal correction, mini open and open techniques can be utilized for osteotomies and/or combined with anterior column realignment techniques. $^{27}$

\section{References}

1. Schwab, F., et al., Adult scoliosis: prevalence, SF-36, and nutritional parameters in an elderly volunteer population. Spine (Phila Pa 1976), 2005. 30(9): p. 1082-5.

2. Johnson, R.D., et al., Pelvic parameters of sagittal balance in extreme lateral interbody fusion for degenerative lumbar disc disease. J Clin Neurosci, 2013. 20(4): p. 576-81.

3. Baghdadi, Y.M., et al., Sagittal balance and spinopelvic parameters after lateral lumbar interbody fusion for degenerative scoliosis: a case-control study. Spine (Phila Pa 1976), 2014. 39(3): p. E166-73.

4. Isaacs, R.E., et al., $A$ prospective, nonrandomized, multicenter evaluation of extreme lateral interbody fusion for the treatment of adult degenerative scoliosis: perioperative outcomes and complications. Spine (Phila $\mathrm{Pa}$ 1976), 2010. 35(26 Suppl): p. S322-30.

5. Glassman, S.D., et al., Correlation of radiographic parameters and clinical symptoms in adult scoliosis. Spine (Phila Pa 1976), 2005. 30(6): p. 682-8.

6. Kepler, C.K., et al., Factors influencing segmental lumbar lordosis after lateral transpsoas interbody fusion. Orthop Surg, 2012. 4(2): p. 71-5.

7. Pinheiro J, B.D., DebRoy S, Sarkar D and R Core 
Team,_nlme:Linear and Nonlinear Mixed Effects Models, in $R$ package version 3.1-118. 2014.

8. Team, R.C., $R$ : A language and environment for statistical computing. , R.F.f.S. Computing, Editor. 2013: Vienna, Austria.

9. Hothorn T, B.F., Westfall P, Simultaneous Inference in General Parametric Models. Biometrical Journal, 2008. 50(3): p. 346-363.

10. Oskouian, R.J., Jr. and C.I. Shaffrey, Degenerative lumbar scoliosis. Neurosurg Clin N Am, 2006. 17(3): p. 299-315, vii.

11. Glassman, S.D., et al., The impact of positive sagittal balance in adult spinal deformity. Spine (Phila Pa 1976), 2005. 30(18): p. 2024-9.

12. Mendoza-Lattes, S., et al., Natural history of spinopelvic alignment differs from symptomatic deformity of the spine. Spine (Phila Pa 1976), 2010. 35(16): p. E792-8.

13. Kotwal, S., et al., Degenerative scoliosis: a review. Hss j, 2011. 7(3): p. 257-64.

14. Ploumis, A., et al., A correlation of radiographic and functional measurements in adult degenerative scoliosis. Spine (Phila Pa 1976), 2009. 34(15): p. 1581-4. 15. Park, P., et al., Comparison of two minimally invasive surgery strategies to treat adult spinal deformity. $\mathrm{J}$ Neurosurg Spine, 2015: p. 1-7.

16. Gupta, M.C., Degenerative scoliosis. Options for surgical management. Orthop Clin North Am, 2003. 34(2): p. 269-79.

17. Di Silvestre, M., F. Lolli, and G. Bakaloudis, Degenerative lumbar scoliosis in elderly patients: dynamic stabilization without fusion versus posterior instrumented fusion. Spine J, 2014. 14(1): p. 1-10.

18. Pavlov, P.W., et al., Good outcome and restoration of lordosis after anterior lumbar interbody fusion with additional posterior fixation. Spine (Phila Pa 1976), 2004. 29(17): p. 1893-9; discussion 1900.

19. Hsieh, P.C., et al., Anterior lumbar interbody fusion in comparison with transforaminal lumbar interbody fusion: implications for the restoration of foraminal height, local disc angle, lumbar lordosis, and sagittal balance. J Neurosurg Spine, 2007. 7(4): p. 379-86. 20. Sasso, R.C., et al., Analysis of operative complications in a series of 471 anterior lumbar interbody fusion procedures. Spine (Phila Pa 1976), 2005. 30(6): p. 670-4.

21. Dakwar, E., et al., Early outcomes and safety of the minimally invasive, lateral retroperitoneal transpsoas approach for adult degenerative scoliosis. Neurosurg Focus, 2010. 28(3): p. E8.

22. Acosta, F.L., et al., Changes in coronal and sagittal plane alignment following minimally invasive direct lateral interbody fusion for the treatment of degenerative lumbar disease in adults: a radiographic study. J Neurosurg Spine, 2011. 15(1): p. 92-6.

23. Wang, M.Y. and P.V. Mummaneni, Minimally invasive surgery for thoracolumbar spinal deformity: initial clinical experience with clinical and radiographic outcomes. Neurosurg Focus, 2010. 28(3): p. E9. 24. Karikari, I.O., et al., Extreme lateral interbody fusion approach for isolated thoracic and thoracolumbar spine diseases: initial clinical experience and early outcomes. J Spinal Disord Tech, 2011. 24(6): p. 368-75. 25. Gelb, D.E., et al., An analysis of sagittal spinal alignment in 100 asymptomatic middle and older aged volunteers. Spine (Phila Pa 1976), 1995. 20(12): p. 1351-8.

26. Hammerberg, E.M. and K.B. Wood, Sagittal profile of the elderly. J Spinal Disord Tech, 2003. 16(1): p. 44-50.

27. Wang, M.Y., Miniopen pedicle subtraction osteotomy: surgical technique and initial results. Neurosurg Clin N Am, 2014. 25(2): p. 347-51.

\section{Disclosures E COI}

Daniel Blizzard, Christopher Brown, Megan Eure, Michael Gallizzi, Charles Sheets, and Benjamin Smith report no financial disclosures or conflicts of interest. Robert Isaacs reports receiving consultancy, grants, and royalties from NuVasive, Inc.; ownership interest in SafeRay Spine, LLC; ownership interest in SafeWire, LLC; ownership interest in VilaSpine, Ltd.; ownership interest in Vertera Spine; travel reimbursement from the ASsociation for Collaborative Spine Research; and ownership interest in Providence Medical Technology.

\section{Corresponding Author}

Daniel J. Blizzard, MD, MHS, Duke University Medical Center, Box 2807, 335 Baker House, 200 Trent Drive, Durham, NC 27710. daniel.blizzard@duke.edu. 
Published 25 August 2016.

This manuscript is generously published free of charge by ISASS, the International Society for the
Advancement of Spine Surgery. Copyright @ 2016

ISASS. To see more or order reprints or permissions, see http://ijssurgery.com. 